\title{
Comportamento estratégico dos frigoríficos no programa de carne angus certificada: proposta de instrumento metodológico
}

Elton Eustáquio Casagrande

Doutor em Economia FGV/SP e na Washinghon Universtiy (St. Louis) com Pós-Doutorado na Universidade Federal do Rio de Janeiro

elton.eustaquio@unesp.br

Gustavo Adolpho Maranhão Aguiar

Mestre em Administração pela Unesp/FCAV. Zootecnista formado pela UENF. Coordenador de Marketing na Barenbrug do Brasil.

guamaguiar@gmail.com

David Ferreira Lopes Santos

Pós-Doutor e Doutor em Administração de Empresas pela Universidade Presbiteriana Mackenzie. david.lopes@unesp.br

\section{Editor Científico: José Edson Lara}

Organização Comitê Científico

Double Blind Review pelo SER/OJS

Recebido em 26.10.2018

Aprovado em 07.03.2019 


\title{
Resumo
}

Este relato propõe uma metodologia que permite identificar e classificar o comportamento estratégico empresarial. Realizou-se um estudo setorial dos frigoríficos brasileiros que produzem carne de alta qualidade por meio do Programa Carne Angus Certificada, tendo em vista que estas empresas, em estrutura de oligopólio, são mais prospectoras e analíticas para as dimensões organizacionais apontadas na literatura. Os procedimentos metodológicos envolveram: i) fundamentos teóricos e empíricos que abordam o comportamento empresarial a partir do estudo seminal de Miles and Snow (1978); ii) concepção do instrumento metodológico para identificação do comportamento estratégico predominante dentro de uma empresa; iii) aplicação e validação do modelo nas quatro principais empresas do setor no Brasil. Os resultados demonstram que os comportamentos prospectivo e analítico são predominantes nos principais processos decisórios, mas existem evidências de comportamento defensivo. As evidências desse relato geram implicações teóricas quanto ao instrumento metodológico e prática ao demonstrar as formas de comportamentos estratégicos.

Palavras Chaves: Certificação; Diferenciação; Oligopólio; Processo Decisório; Proteína Animal.

\section{Strategic behavior of slaughterhouse in the certified angus meat program: methodological instrument proposal}

\begin{abstract}
This report proposes a methodology that allows identifying and classifying the strategic business behavior. A sectorial study of the Brazilian slaughterhouses that produced high-quality meat through the Certified Angus Meat Program was carried out, considering that these companies, in an oligopoly structure, are more prospective and analytical for the organizational dimensions pointed out in the literature. The methodological procedures involved: i) theoretical and empirical foundations that approach business behavior from the seminal study of Miles and Snow (1978); ii) design of the methodological instrument to identify the predominant strategic behavior within a company; iii) application and validation of the model in the four main companies in the sector in Brazil. The results show that prospective and analytical behavior are predominant in the main decision-making processes, but there is evidence of defensive behavior. The evidences of this report generate theoretical implications regarding the methodological and practical instrument when demonstrating the strategic behavior forms.
\end{abstract}

Keywords: Certification; Differentiation; Oligopoly; Decisional process; Animal Protein.

\section{Comportamiento estratégico de los frigoríficos en el programa de carne angus certificada: propuesta de instrumento metodológico}

\section{Resúmen}

Este relato propone una metodología que permite identificar y clasificar el comportamiento estratégico empresarial. Se realizó un estudio sectorial de los frigoríficos brasileños que 
producen carne de alta calidad por medio del Programa Carne Angus Certificada, teniendo en vista que estas empresas, en estructura de oligopolio, son más prospectoras y analíticas para las dimensiones organizacionales apuntadas en la literatura. Los procedimientos metodológicos involucra: i) fundamentos teóricos y empíricos que abordan el comportamiento empresarial a partir del estudio seminal de Miles and Snow (1978); ii) concepción del instrumento metodológico para identificar el comportamiento estratégico predominante dentro de una empresa; iii) aplicación y validación del modelo en las cuatro principales empresas del sector en Brasil. Los resultados demuestran que los comportamientos prospectivo y analítico son predominantes en los principales procesos de toma de decisiones, pero existen evidencias de comportamiento defensivo. Las evidencias de este relato generan implicaciones teóricas en cuanto al instrumento metodológico y práctico al demostrar las formas de comportamientos estratégicos.

Palabras claves: Certificación; la diferenciación; Oligopólio; Procedimiento Decisório; Proteína Animal.

\section{Introdução}

O setor de carne bovina brasileira é relevante para a segurança alimentar do mercado nacional e internacional. Os dados do Instituto Brasileiro de Geografia e Estatística (IBGE) apontam para estoque final de bovinos no Brasil em 2016 de 218,23 milhões de cabeças, 37,9\% maior do que o efetivo em 1996 (IBGE, 2016). Trata-se do maior rebanho comercial mundial. Em escala global, o país detém, atualmente, a segunda maior produção mundial de carne bovina, estando atrás apenas dos Estados Unidos, com a produção estimada em 11,51 milhões de ton para 2016 (USDA, 2017).

Igualmente a qualquer ambiente empresarial, o setor de carne bovina é constituído de relações institucionais e organizacionais que difundem o aprendizado do comportamento estratégico entre os atores. As informações analisadas neste relato são provenientes da alta gerência dos quatro principais frigoríficos do Estado de São Paulo, que têm investido em diferenciação do produto cárneo, por meio da certificação privada. As empresas selecionadas são as líderes de mercado e constituem uma estrutura de concorrência na forma de oligopólio.

Este relato utiliza a taxinomia Miles e Snow (1978) para as dimensões empresariais relevantes que são atualizadas e discutidas frente aos achados teóricos recentes. As evidências coletadas fornecem elementos e características do comportamento predominante de cada uma das quatro empresas entrevistadas.

A hipótese que organiza o trabalho é de que os comportamentos estratégicos das empresas em estrutura de oligopólio são mais prospectoras e analíticas para as dimensões 
empresariais estudadas. Em decorrência, o comportamento estratégico pode ser captado através de um instrumento metodológico e também pode ser replicado para outros segmentos empresariais.

O comportamento estratégico visa agregar valor através de ações organizadas na adaptação às mudanças de mercado (Krishnamoorthi \& Mathew, 2018). Por se tratarem de empresas de grande porte as estruturas administrativas permitem a elaboração de um plano de trabalho e planejamento de longo prazo.

Os resultados obtidos com o plano de trabalho e questões são um laboratório para a compreensão da maneira que o comportamento estratégico expressado na literatura se apresenta junto à realidade empírica. Por isso, este estudo se enquadra na forma de "artigo tecnológico" ou "relato tecnológico" que segundo Anwar, Shah e Hasnu (2016), e Child, Hsieh, Elbanna, Karmowska, Marinova, Puthusserry, Tsai, Narooz e Zhang (2017) demonstram a relevância de mapear comportamento, acolher inovações e orientar decisões de cunho aplicado no âmbito das organizações.

A contribuição consiste na propositura de uma metodologia que permite a identificação do comportamento estratégico e sua transferência como mecanismo de aprendizado para outras empresas. A pergunta que norteia o estudo é: como uma empresa pode identificar e propor um comportamento estratégico adequado diante de sua estrutura de competição?

Diante disso, o relato está estruturado como se segue. Além desta introdução, a seção 2 que trata do contexto da indústria investigada e as características setoriais do ambiente estudado. Na seção 3 desenvolve-se um diagnóstico do comportamento estratégico segundo a literatura selecionada a partir do critério de contribuições que elegeram coletas de dados e questionários semiestruturados para a realização de suas investigações e também estudos quantitativos.

A base de dados da literatura selecionada provém da Plataforma Scopus. Na seção 4 tem-se o plano de trabalho com questões avaliativas, extraído das contribuições da literatura recente e que ampliaram o escopo do ciclo adaptativo. A literatura forneceu os núcleos de contribuições que deram sustentação às perguntas avaliativas, concebidas para revelar o tipo de comportamento que mais caracteriza uma organização produtiva. Nessa seção, estão os procedimentos metodológicos e em suas subdivisões demonstra-se a proposta da intervenção (4.1) e das contribuições tecnológicas segmentadas nas subseções 4.2 e 4.3. Finalmente, as conclusões e observações finais são elencadas na seção 5, que enfatizam os resultados 

Ferreira Lopes Santos

estratégicos comportamentais prospectivos e analíticos e a concepção do plano de trabalho com os questionamentos direcionados que permitem alcançar o diagnóstico em termos do comportamento predominante.

\section{Contexto empírico do segmento da indústria de frigoríficos}

A característica principal da oferta do regime de oligopólio é a capacidade das empresas de fixar o mark-up mais próximo do que definem como necessário para remunerar o investimento realizado. O que a empresa não controla é a demanda, mas o porte e domínio de mercado permitem maior liberdade para fixar o mark-up. A equação (1) ilustra a condição:

$$
P=\mu(L) *\left(\frac{W}{F^{\prime}(L)}\right)
$$

onde $P=$ preços; $\mu=$ markup $; \frac{W}{F^{\prime}(L)}=$ salário real.

Ao produzirem um produto alimentício com elasticidade próxima a unidade e de alta frequência nos gastos do orçamento familiar, a quantidade demandada sofre menos ajustes quando há flutuação da renda nacional. Em termos empíricos, a flutuação das quantidades produzidas é maior do que a flutuação dos preços no curto prazo. Sob preços rígidos a gerência das empresas consegue manter o mark up estável ou acíclico em relação a demanda por trabalho. O que não se observa na equação (1) são os comportamentos estratégicos que norteiam a formação de preço e busca de mercado por parte das empresas. Mesmo os atributos ou diferenciação dos produtos não são facilmente observados na estrutura de oferta, senão por estudos de caso.

$\mathrm{Na}$ estrutura de concorrência na forma de oligopólio que caracteriza a produção de carne bovina o produto é uma commodity e representa um efeito da produção globalizada (Leonelli \& Oliveira, 2016). Mas, há um movimento de segmentação de mercado em curso, com destaque para o surgimento de nichos de consumo orientados para atributos de qualidade diferenciados. Há um aumento no número de marcas e estabelecimentos que oferecem carne bovina com alto valor agregado. Embora seja considerado um nicho, o mercado das carnes diferenciadas ou "gourmet" tem potencial de crescimento elevado, pautado em diferenciação de produtos e de serviços.

A presença de estabelecimentos especializados são indícios da segmentação de mercado mundial segundo Berian, Sánchez e Carr (2009), Champredonde (2008), Polkinghorne e Thompson (2010), Schnettler (2014) e nos Estados Unidos analisado por Siebert \& Jones 
(2013). Dessa maneira, os frigoríficos procuram reduzir o efeito das características de produto homogéneo do produto cárneo, através da diferenciação.

As certificações são mecanismos para atestar a diferenciação de determinado produto em relação a seus concorrentes para os consumidores (Martinelli, Pigatto \& Machado 2015) e um meio para diferenciar e agregar valor até mesmo à carne bovina, produto que por muito tempo foi considerado uma commodity, apresentando pouco espaço para diferenciação.

Quanto a importância de novos aspectos que interferem na matriz de competição original há o grau de inovação tanto na criação/procriação, trato e manejo do animal quanto na melhoria da produtividade do rebanho e pasto (Martinelli, Pigatto \& Machado 2015).

Em 2006 as empresas JBS, MARFRIG, BRF e MINERVA eram responsáveis por 26\% dos abates de bovinos no país. O percentual evoluiu para 56,5\% em 2015. As quatro empresas abatem cerca de $60 \%$ do rebanho bovino total do país (Carvalho, 2016).

A análise dos elos à montante da indústria frigorífica segundo (Wedekin, 2017) demonstra que o setor de produção de bovinos de corte aproxima-se da concorrência perfeita o que favorece grandes redes de supermercado que não diferenciam o produto, apesar de o produto bovino não ser homogêneo (distingue-se entre raças, regiões, idades e sistemas de produção). Mas no mercado spot é tratado como commodity.

À jusante do elo industrial estão os compradores com presença de grandes empresas com elevada capilaridade, alta capacidade de giro dos estoques próximos ao consumidor. $\mathrm{O}$ poder de barganha também é influenciado pela quantidade de fornecedores e pela existência de produtos substitutos. A diversificação de atividades e a diferenciação de produtos para o mercado doméstico são praticadas pelas indústrias de processamento e pelos varejistas, que comercializam itens com marcas, cortes e embalagens (Wedekin, 2017).

\section{Diagnóstico da situação investigada segundo a literatura recente}

O comportamento estratégico é resultado de uma orientação que tem como evidências internacionais o aprendizado informacional sobre o ambiente de competição, inovação e buscas por oportunidades Velean, Shoam e Asseraf (2014).

Dos inúmeros modelos e sistemas de classificação de estratégias propostas, a Tipologia Estratégica de Miles e Snow (1978) apresenta significância em inúmeros trabalhos, sendo o mais utilizado, praticado, verificado e submetido a vários testes de validade e de utilização 

Ferreira Lopes Santos

prática de acordo com Hambrick, (2003), Anwar, Shah e Hasnu (2016), e Child et. al. (2017). Nesse último estudo, os autores aplicam uma metodologia executada por questionário que caracteriza o modelo e o comportamento em negócios de pequenas e médias empresas com atuação internacional. Os autores buscam descobrir se há um modelo de negócio predominante para atuação internacional e o perfil de comportamento.

As variáveis de investigação são: 1. intensidade do $\mathrm{P} \& \mathrm{D}$ (com base no número relativo de pessoas neste departamento); 2. lançamento de produtos; 3 . força competitiva; 4. redes de relacionamento no mercado; 5. perfil mercadológico; 6. experiência em comércio internacional; 7. tamanho dos ativos.

Segundo Lopes, Moura e Oliveira (2010), a tipologia proposta por Miles e Snow (1978) contribui de maneira significativa para a área de administração por oferecer uma interpretação sobre a forma que empresas se adaptam em seu ambiente e os motivos que justificam diferentes estratégias para obter eficiência e a eficácia de seus processos. Miles e Snow (1978) utilizaram a ideia de um ciclo de adaptação para elaborar uma tipologia de comportamento, segundo a qual o alinhamento da organização com o seu ambiente deverá ocorrer por meio de um ciclo existente em todas as organizações, sendo identificado com maior facilidade nas organizações que passaram por um rápido crescimento, que saíram recentemente de uma crise ou promovido em novas organizações.

Para Hakansson e Snehota (2006), a base da Tipologia Estratégica de Miles e Snow é que a organização precisa estar ajustada ao seu ambiente, fazendo frente à concorrência de maneira eficiente e eficaz. Encontrou-se em Olson, Slater, Hult e Olson (2018) uma investigação entre comportamento de gerência de marketing e o desempenho em termos de vantagem competitiva de acordo com a estratégia mercadológica. O modelo do questionário parte da estratégica do modelo de negócio classificado em: 1. prospectivo; 2. analítico; 3. de baixo custo - defensivo; 4. defensivo.

A estratégia mercadológica tem como diretrizes: 1. agressiva quando baseada em marketing para produtos e serviços inovadores; 2 . massificada quando se trata de produtos de baixa inovação sem diferenciação; 3. minimalistas que oferecem baixa qualidade de serviços com atividades limitadas de marketing; 4 . de alto valor quando se trata de canais de distribuição de alta qualificação de serviços mas com preços menores do que a opção agressiva.

A aliança entre a estratégia do modelo de negócio e de marketing encontram nas políticas mercadológicas definidas pelas empresas como meio para obter o desempenho estipulado no planejamento estratégico. 
Os autores trabalharam com dois tipos de amostras com empresas que: 1. alinham seu plano de negócios a estratégias mercadológicas; 2. que não apresentam o referido alinhamento. A realização do estudo compreendeu 256 empresas. Os resultados demonstram que quanto maior a aderência do plano de negócios com a estratégia mercadológica tanto melhor o desempenho das empresas.

Krishnamoorthi e Mathew (2018) analisaram a questão da aderência entre a criação de valor e as ações estratégicas. O referencial teórico dos autores compreende a análise de negócios e o desempenho de dois grupos empresariais, sendo um deles uma empresa do agronegócio. A unidade de análise é o investimento em tecnologia e o desempenho de corporações.

Este relato analisa cinco dimensões de capacidades analíticas empresariais (1. Investimento em ativos tecnológicos; 2. Capacidade analítica; 3. Vetores da capacidade empresarial; 4. Desempenho do negócio; 5. Variáveis de controle). Para cada dimensão os autores associam conceitos precisos que traduzem o contexto de cada dimensão. Após os conceitos há indicação das variáveis para cada conceito que instrumentaliza cada dimensão.

A intervenção no ambiente empresarial por parte dos autores é conduzido por questionário semiestruturado. $\mathrm{O}$ texto das entrevistas foi codificado e processado (software Nvivo 10). A análise do programa gerou uma análise dos discursos com as devidas associações entre as capacidades segundo as dimensões e uma avaliação do desempenho empresarial em termos do retorno dos ativos. As variáveis de controle foram identificadas com os fatores institucionais: ambiente competitivo, fatores de mercado e regulação.

Com base nos relatórios das entrevistas os autores criaram quatro níveis de variáveis organizacionais que acolhem as tipologias de comportamento estratégico: 1. Metas empresariais e a natureza das decisões; 2. Capacidade da gestão de padronizar processos derivados de adaptação frente a investimentos; 3 . Formas da estratégia analítica dos dois grupos entrevistados; 4. Meios para colocar em ação as formulações analíticas estratégicas, como por exemplo orientações verbais através de reuniões de dirigentes para suas equipes.

A contribuição dos autores consiste em um método analítico de avaliação de negócios com foco em comportamento com base na robustez de questionário semiestruturado. As dimensões empresariais e administrativas são elucidadas a partir das questões produtivas e de mercado (Krishnamoorthi e Mathew, 2018).

A forma de captar as adaptações a partir do comportamento estratégico empresarial está cercada de interferências e depende da capacidade das equipes diretivas e suas gerências. Se no 

Ferreira Lopes Santos

artigo acima o foco recaiu na leitura do comportamento estratégico, os processos de ajustamento podem ser melhor observados por Saebi, Lien e Foss (2017). O contexto macroeconômico é a crise financeira de 2008 e a investigação procurou identificar as mudanças ou adaptações do plano de negócios de 1.248 empresas de uma população de 5.000 empresas norueguesas (Saebi, Lien e Foss, 2017).

Os autores identificam dois aspectos através dos quais a investigação do processo de adaptação empresarial ocorre. O primeiro se deve a capacidade de cognição do corpo diretivo da corporação e o segundo é o efeito de ameaças (efeito negativo) ou de oportunidades (efeito positivo) sobre o comportamento empresarial e as respostas (Saebi, Lien e Foss, 2017, p.567).

Damke, Gimenez e Damke (2018) associaram variáveis estratégicas e comportamento ao desempenho de 228 micro e pequenas empresas do segmento de confecção da cidade de Curitiba em 2013. Os dados coletados eram qualitativos e procuraram avaliar o processo de desenvolvimento da estratégia, conteúdo, modo administrativo, sendo a atitude empreendedora e a incerteza àquelas que mais afetaram o desempenho.

O ciclo adaptativo tem como pressuposto a existência de um modelo de negócio. Saebi, Lien e Foss (2017) ressaltam a existência de pelo menos 12 conceitos diferentes de modelo. A existência de um plano de negócios não deve ser apenas intuitiva, do contrário a adaptação não pode ser observada. Um segundo aspecto dos autores acima é quanto a diferença entre uma adaptação ao plano, oriunda de fatores externos ou internos que procuraram moldar a demanda ou uma inovação que pode conduzir a um outro modelo de negócio.

A metodologia do estudo de Saebi, Lien e Foss (2017) teve maior influência na elaboração deste instrumento de pesquisa, junto aos demais resenhados devido a interação de três formas metodológicas que subsidiaram o questionário: 1. A objetividade das possibilidades de manifestação de comportamento a partir de itens pertinentes a novos produtos, fornecedores, parceiros, formação de preço, esforço de vendas e reorganização produtiva; 2. A objetividade das possibilidades quanto aos efeitos de novas soluções, lançamento de produtos e serviços, $\mathrm{P} \& \mathrm{D}$, redução e custos, melhoria de processos e alteração de preços sobre a concorrência; 3 . Os autores utilizaram da escala Likert para dar gradação das respostas referentes aos efeitos da crise financeira de 2008 sobre o comportamento empresarial com foco na concorrência (problema empresarial), produtivo e administrativo. 


\section{Procedimentos metodológicos, formas de intervenção e contribuições tecnológicas}

O procedimento metodológico do estudo tem como forma: 1. identificação de contribuições recentes sobre comportamento estratégico de Miles \& Snow (1978) nas dimensões empresarial (mercado), de engenharia (estrutura produtiva) e administrativa (coordenação estratégica das áreas e os desafios com relação a estrutura de mercado); 2. avaliação dos procedimentos metodológicos da literatura recente, de seus instrumentos e formas de intervenção empregadas; 3. elaboração e adequação dos questionamentos sob a concepção de plano de trabalho para extração do conteúdo pertinente a taxinomia de comportamento de Miles e Snow (1978); 4. proposição de um instrumento de transferência de conhecimento das diretrizes e questionamentos para identificação do comportamento estratégico predominante. $\mathrm{O}$ procedimento visa melhorar a percepção das Diretorias das empresas sobre decisões para diferenciar produtos dentro de regime de concorrência em que se inserem.

O plano de trabalho acolhe a visão de que a estratégia é uma determinação de metas e objetivos de longo prazo de uma empresa de acordo com a estrutura organizacional (Chandler, 1962). A estratégia compreende ações coerentes e decisões consistentes com coordenação entre áreas de uma empresa e os desafios de mercado (Chandler, 1962).

A escolha do modelo de negócio define a arquitetura da atividade e uma vez estabelecido há dificuldades para alterá-lo (Teece, 2010). O autor se vale de evidências de estudos de casos como das companhias American Express e Discover Card frente a Visa e Mastercard. Essa é uma ilustração, por exemplo, da necessidade de adaptação das competências empresariais.

No mercado brasileiro, por exemplo, a agroindústria compreende um segmento dinâmico e de grandes dimensões, como apontou-se no início deste trabalho. A diversidade de tamanho de empresas é elevada, e para o segmento cárneo, objeto da análise do presente relato o comportamento do consumidor é muito relevante. Esse comportamento consiste, a nosso ver, no vetor determinante das principais adaptações que são necessárias mesmo para empresas em regime de oligopólio. 


\subsection{Forma da Intervenção - a definição do plano e das questões avaliativas}

O ciclo adaptativo de Miles e Snow (1978) é representado pela figura abaixo. Para Hakansson e Snehota (2006) a base da Tipologia Estratégica de Miles e Snow é que a organização precisa estar ajustada ao seu ambiente.

O ponto de partida é o problema empresarial que define a natureza de um negócio e sua expressão no mercado, seguido das questões técnicas e/ou tecnológicas da estrutura industrial da firma e, finalmente, a racionalidade da gestão administrativa. As conexões entre essas três áreas são organizadas, de maneira geral, de forma tácita quando observa-se o mercado.

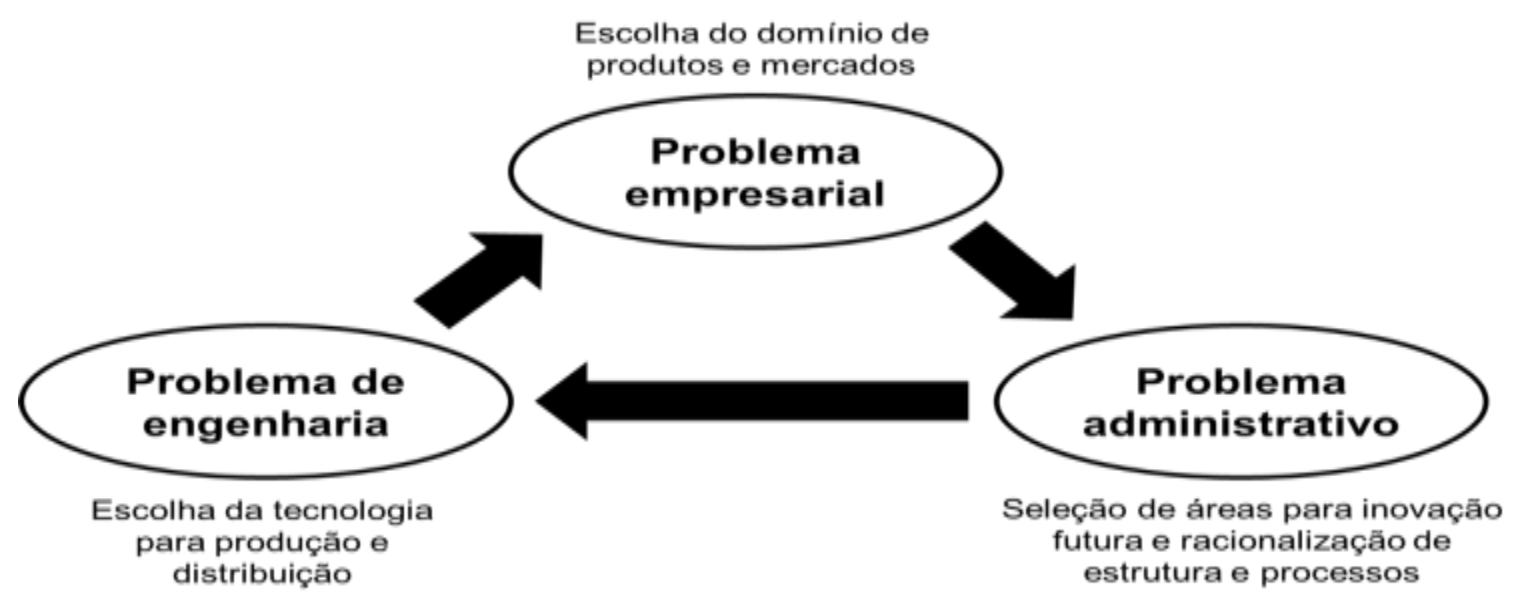

Figura. O ciclo adaptativo proposto por Miles e Snow Fonte: Miles e Snow (1978)

O ciclo adaptativo é direcionado para solucionar três tipos de problemas interligados e que dependem de escolhas estratégicas realizadas pelos tomadores de decisão em resposta ao ambiente competitivo.

O problema empresarial está relacionado ao desenvolvimento de inovações, com o objetivo de fortalecer a posição competitiva. A engenharia envolve a criação de processos tecnológicos mais adequados ao mercado. A administração se estrutura para gerenciar a implementação das soluções para os dois primeiros problemas (Caetano, 2013).

Miles e Snow (1978) propõem a existência de quatro tipos de estratégias para tratar dos problemas com ações coerentes e complementares entre si: Prospectora, Defensiva, Analítica e Reativa (P-D-A-R), sintetizadas no Quadro 1.

A estratégia "Prospectora" desenvolve novas tecnologias e produtos para explorar oportunidades de mercado que viabilizem o crescimento da organização por meio da inovação. Se caracterizada pela flexibilidade operacional e descentralização de controles e poder. As 
empresas "Prospectoras" tendem a ser as pioneiras, com posição competitiva agressiva, e constante busca por oportunidades. A inovação tecnológica para as empresas Prospectoras é sinônimo de lucratividade (DeSarbo et al., 2005), rapidez na produção e comercialização da diferenciação Malone et al. (2008).

A estratégia "Defensiva" surge quando há mercados já conquistados e há necessidade de manter um mercado específico. Esta estratégia é apropriada para empresas que atuam em ambientes estáveis. A ação é o controle de qualidade, eficiência, o que limita de certa forma a flexibilidade operacional, com controles e tomada de decisão centralizados. Nessa estratégia a tecnologia é fundamental dada a relação eficiência - custos e processos (Miles \& Snow, 1978). A estratégia "Analítica" consiste em uma forma híbrida das estratégias "Prospectora" e "Defensiva", com o objetivo de competir em eficiência e manter o foco nas inovações. Porém, se enfrenta custos mais altos e dificuldades em alcançar eficiência devido ao foco duplo. A estratégia "Reativa" reflete adaptação instável ao ambiente, diante de uma reação inconsistente entre sua estratégia e organização administrativa e tecnológica pouco apropriada às mudanças ambientais. É uma espécie de não estratégia, não possuindo nenhum plano ou mecanismos e processos para competir e se adaptar ao mercado.

\begin{tabular}{|c|c|}
\hline $\begin{array}{c}\text { Tipologia de } \\
\text { Comportamento }\end{array}$ & Características \\
\hline Prospectora & $\begin{array}{l}\text { Busca oportunidade no mercado experimentando respostas às tendências do } \\
\text { ambiente. Criam incertezas e mudanças às quais os concorrentes devem } \\
\text { responder. }\end{array}$ \\
\hline Defensiva & $\begin{array}{c}\text { Possui um estreito domínio produto-mercado, seus executivos são altamente } \\
\text { especializados em determinadas áreas de operações, mas não procura } \\
\text { oportunidades fora de seu domínio. Raramente necessita de ajustes na sua } \\
\text { estrutura, operações e tecnologia. }\end{array}$ \\
\hline Analítica & $\begin{array}{l}\text { Opera em dois tipos de domínios produto-mercado. Os estrategistas } \\
\text { organizacionais observam as novas ideias dos concorrentes, adotando } \\
\text { rapidamente aquelas que aparentam ser mais promissoras. }\end{array}$ \\
\hline Reativa & $\begin{array}{l}\text { Percebe as alterações do ambiente e suas incertezas, mas pela inexistência de } \\
\text { uma relação estratégia-estrutura raramente realiza ajustes, a não ser que seja } \\
\text { forçada por pressões ambientais. }\end{array}$ \\
\hline
\end{tabular}

Quadro 1. Tipologia de Comportamentos e Características.

Fonte: Miles e Snow (1978).

Connant, Mokwa e Varadarajan (1990) incrementam o ciclo adaptativo com onze dimensões sintetizados no Quadro 2. 


\begin{tabular}{|c|c|c|}
\hline $\begin{array}{l}\text { Etapa do ciclo } \\
\text { adaptativo }\end{array}$ & Dimensões & Descrição \\
\hline \multirow{4}{*}{ 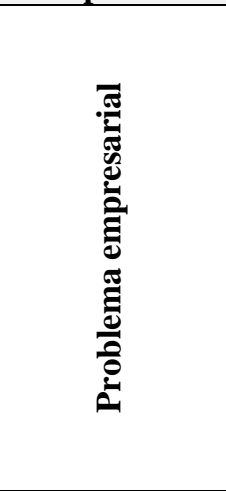 } & $\begin{array}{c}\text { Domínio de produtos e } \\
\text { processos }\end{array}$ & $\begin{array}{l}\text { Analisa os produtos da empresa em função do grau de } \\
\text { inovação, natureza, estabilidade, foco, consistência, etc. }\end{array}$ \\
\hline & Postura de sucesso & $\begin{array}{c}\text { Analisa a postura da empresa com base na quantidade e } \\
\text { qualidade dos produtos que oferece, no grau de inovação das } \\
\text { ideias que adota, na forma como aproveita as oportunidades } \\
\text { do mercado, etc. }\end{array}$ \\
\hline & Monitoramento ambiental & $\begin{array}{l}\text { Analisa a empresa com base no tempo dispensado com o } \\
\text { monitoramento das mudanças e tendências no mercado. }\end{array}$ \\
\hline & Crescimento & $\begin{array}{l}\text { Analisa o crescimento da empresa em termos das práticas } \\
\text { desenvolvidas para servir os mercados atuais e potenciais, } \\
\text { quanto ao grau de penetração, concentração, agressividade e } \\
\text { diversificação. }\end{array}$ \\
\hline \multirow{3}{*}{ 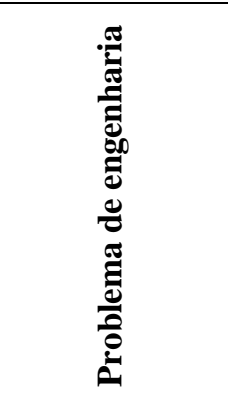 } & Objetivo tecnológico & $\begin{array}{c}\text { Analisa as metas da empresa em função da dedicação e } \\
\text { compromisso relativos à manutenção dos custos sob controle, } \\
\text { à análise dos custos e receitas, à geração seletiva de novos } \\
\text { produtos e à entrada em novos mercados. }\end{array}$ \\
\hline & Amplitude tecnológica & $\begin{array}{l}\text { Caracteriza as competências e habilidades dos executivos das } \\
\text { empresas em função da análise das tendências, grau de } \\
\text { especialização, amplitude, empreendedorismo e fluidez. }\end{array}$ \\
\hline & $\begin{array}{l}\text { Anteparos tecnológicos } \\
\text { (buffers) }\end{array}$ & $\begin{array}{l}\text { Analisa as vantagens da empresa em relação aos concorrentes } \\
\text { com base na capacidade de aproveitamento das } \\
\text { oportunidades, respondendo a elas com produtos coerentes. }\end{array}$ \\
\hline \multirow{4}{*}{  } & Coalizão dominante & Analisa a orientação dos principais executivos. \\
\hline & Planejamento & $\begin{array}{l}\text { Analisa a orientação da empresa em função da forma como } \\
\text { analisa o seu mercado e se prepara para enfrentá-lo. }\end{array}$ \\
\hline & Estrutura & Analisa a natureza da estrutura da empresa. \\
\hline & Controle & $\begin{array}{l}\text { Analisa os procedimentos adotados pela empresa para } \\
\text { analisar seu desempenho em função do grau de centralização. }\end{array}$ \\
\hline
\end{tabular}

Quadro 2. Etapas do Ciclo Adaptativo, Dimensões e Descrições.

Fonte: Connant, Mokwa e Varadarajan (1990).

Com base no Quadro 2 conectou-se as dimensões expandidas por Connant, Mokwa e Varadarajan (1990) com as contribuições da literatura recente para que o nosso plano de trabalho se encontrasse atualizado. Com isso, a contribuição teórica deste contempla evidências recentes sobre comportamento estratégico (Quadro 3).

\begin{tabular}{|c|c|c|}
\hline Núcleo das Contribuições & Autores & Classe de Problema \\
\hline 1. Produtos e processos & Velean, Shoham e Asseraf, (2014) & Empresarial \\
\hline 2. Imagem da empresa & Saebi, Lien, Foss (2017) & Empresarial \\
\hline 3. Monitoramento de mercado & $\begin{array}{l}\text { Olson, Slater, Hult e Olson (2018); Saebi, Lien, } \\
\text { Foss (2017) }\end{array}$ & Empresarial \\
\hline $\begin{array}{l}\text { 4. Características que impactam a } \\
\text { demanda / Crescimento }\end{array}$ & Damke, Gimenez, Damke (2018) & Empresarial \\
\hline 5. Perfil estratégico da empresa & $\begin{array}{l}\text { Krishnamoorthi e Mathew (2018); } \\
\text { Olson, Slater, Hult e Olson (2018); Saebi, Lien, } \\
\text { Foss (2017) }\end{array}$ & Engenharia \\
\hline
\end{tabular}




\begin{tabular}{|l|l|l|}
\hline $\begin{array}{l}\text { 6. Competências dos funcionários } \\
\text { de nível gerencial (Amplitude) }\end{array}$ & $\begin{array}{l}\text { Olson, Slater, Hult e Olson (2018); Ribeiro, } \\
\text { Rosseto e Verdinelli (2011) }\end{array}$ & Engenharia \\
\hline $\begin{array}{l}\text { 7. Proteção contra os concorrentes } \\
\text { (Anteparos) }\end{array}$ & $\begin{array}{l}\text { Saebi, Lien, Foss (2017); Hakansson e Snehota } \\
(2006)\end{array}$ & Engenharia \\
\hline $\begin{array}{l}\text { 8. Forma de gerenciamento } \\
\text { (Coalisão) }\end{array}$ & Child, Hsieh e Elbanna, et. al. (2017) & Administrativo \\
\hline $\begin{array}{l}\text { 9. Forma de preparação para o } \\
\text { futuro (Planejamento) }\end{array}$ & $\begin{array}{l}\text { Krishnamoorthi e Mathew (2018); Child, Hsieh e } \\
\text { Elbanna, } \text { et. al. (2017) }\end{array}$ & Administrativo \\
\hline $\begin{array}{l}\text { 10. Estrutura organizacional } \\
\text { Krishnamoorthi e Mathew (2018); }\end{array}$ & Administrativo \\
\hline $\begin{array}{l}\text { 11. Procedimentos de avaliação de } \\
\text { desempenho (Controle) }\end{array}$ & $\begin{array}{l}\text { Krishnamoorthi e Mathew (2018); Heinzen et al. } \\
(2016)\end{array}$ & Administrativo \\
\hline
\end{tabular}

Quadro 3. Núcleo das Contribuições, Autores e Classe

No Quadro 4 estão isoladas o núcleo das contribuições que servem de base para as questões avaliativas, classificadas segundo a tipologia de comportamento. Isolou-se aspectos centrais da literatura recente para constituir questões que expressem três tipos de evidências: 1 . A natureza do comportamento (prospectivo, analítico, defensivo ou reativo); 2 A estrutura organizacional e suas áreas (ou departamentos) de ação estratégica; 3. O monitoramento e meios de organizar as percepções de mudanças no mercado. As condições para a realização das entrevistas foram estabelecidas para fornecer um elevado grau de controle. Em primeiro lugar, a estrutura de mercado e as empresas líderes foram previamente escolhidas.

\begin{tabular}{|l|l|l|}
\hline Autores & $\begin{array}{l}\text { Plano para as Questões } \\
\text { Avaliativas }\end{array}$ & Questões para Classificar o Comportamento \\
\hline $\begin{array}{l}\text { Velean, Shoham } \\
\text { e Asseraf, (2014) } \\
\text { aos concorrentes, } \\
\text { produtos e processos: } \\
\text { Inovadores/Estáveis/Transição } \\
\text { Problema Empresarial }\end{array}$ & $\begin{array}{l}\text { Busca oportunidades antes do Mercado? (P) } \\
\text { Analisa concorrência e age? (A) } \\
\text { Domínio de nicho - qual a forma de defesa? (D) } \\
\text { Limitado a algum ajustamento frente à concorrência } \\
\text { (R) }\end{array}$ \\
\hline $\begin{array}{l}\text { Saebi, Lien, Foss } \\
\text { (2017) }\end{array}$ & $\begin{array}{l}\text { Como garante reputação com inovação à frente da } \\
\text { concorrência? (P) } \\
\text { imagem das emprestido em } \\
\text { Stakeholders/linhas de } \\
\text { produto/novos mercados/esforços } \\
\text { junto a clientes/novos } \\
\text { fornecedores/preços. } \\
\text { Problema Empresarial }\end{array}$ & $\begin{array}{l}\text { O que entende por produtos seletivos e alta qualidade? } \\
\text { Como estrutura a defesa do nicho? (D) } \\
\text { Como a empresa reage às oportunidades ou } \\
\text { ameaças de mercado dado que não se estrutura de } \\
\text { outra forma? (R) }\end{array}$ \\
\hline
\end{tabular}




\begin{tabular}{|c|c|c|}
\hline $\begin{array}{l}\text { Olson, Slater, } \\
\text { Hult e Olson } \\
(2018)\end{array}$ & $\begin{array}{l}\text { 3. Compromissos da organização } \\
\text { com mercado e fatores internos: } \\
\text { planejamento que afetam demanda, } \\
\text { monitoramento de mudanças, } \\
\text { seleção de } \\
\text { metas/treinamento/estimativa / } \\
\text { compensações equipes. } \\
\text { Problema Empresarial }\end{array}$ & $\begin{array}{l}\text { Quais as ferramentas que a empresa utiliza para } \\
\text { monitorar o mercado? (para todos) } \\
\text { Quanto tempo se dedica ao monitoramento? } \\
\text { Resp. Muito e continuamente (P); } \\
\text { Resp. Algum tempo com foco mais restritos em } \\
\text { mudanças (A); } \\
\text { Resp. Mínimo e contido a identificação de ameaças ao } \\
\text { nicho (D); } \\
\text { Resp. Não observa enquanto estratégia (R). }\end{array}$ \\
\hline $\begin{array}{l}\text { Damke, } \\
\text { Gimenez, Damke } \\
(2018)\end{array}$ & $\begin{array}{l}\text { 4. Principais habilidades, } \\
\text { competências, atributos e } \\
\text { impacto sobre a demanda: } \\
\text { Interpretação de mercado / } \\
\text { planejamento estruturado / } \\
\text { idealização de processos / estudos } \\
\text { de mercado. } \\
\text { Problema Empresarial }\end{array}$ & $\begin{array}{l}\text { Quais ações (agressivas) são feitas buscando inovação } \\
\text { em produtos e/ou processos com fundamentos no } \\
\text { planejamento?(P) } \\
\text { Quais os instrumentos de análise e idealizações feitas } \\
\text { frente ao que se observar no mercado e como ilustrar } \\
\text { o efeito das ações internas sobre a demanda?(A) } \\
\text { No monitoramento do nicho de mercado, quais áreas } \\
\text { da empresa são cruciais frente a mudanças } \\
\text { consideradas uma ameaça ao nicho de mercado?(D) } \\
\text { Quais as áreas de maior eficiência e eficácia da } \\
\text { empresa que permitem reagir as mudanças em algum } \\
\text { grau? A empresa, com esse comportamento, perde } \\
\text { mercado anualmente? }\end{array}$ \\
\hline $\begin{array}{l}\text { Krishnamoorthi e } \\
\text { Mathew (2018); } \\
\text { Olson, Slater, } \\
\text { Hult e Olson } \\
\text { (2018); Saebi, } \\
\text { Lien, Foss (2017) }\end{array}$ & $\begin{array}{l}\text { 5. Principais proteções frente aos } \\
\text { concorrentes: } \\
\text { custos/receitas/portfólio } \\
\text { Tipos de ativos / tecnologia / } \\
\text { alinhamento com mercado / } \\
\text { eficiência e eficácia / valor gerado } \\
\text { e agregado. } \\
\text { Problema de Engenharia }\end{array}$ & $\begin{array}{l}\text { Como a empresa garante que pessoas, recursos e } \\
\text { equipamentos estejam disponíveis e acessíveis para o } \\
\text { desenvolvimento de novos produtos, processos e } \\
\text { conquistar novos mercados? Identifique e mensure os } \\
\text { investimentos? (P) Como a empresa analisa os custos } \\
\text { e receitas para mantê-los sob controle? (P) } \\
\text { Como a empresa analisa a entrada em novos } \\
\text { mercados? (A) } \\
\text { Como a empresa mantém os custos sob controle?(D) } \\
\text { Qualifique as ações recentes que a empresa adotou } \\
\text { contra ameaças? (R) }\end{array}$ \\
\hline $\begin{array}{l}\text { Olson, Slater, } \\
\text { Hult e Olson } \\
(2018) ;\end{array}$ & $\begin{array}{l}\text { 6. Competências: } \\
\text { Capacidade de resposta das } \\
\text { equipes e a estrutura de } \\
\text { planejamento. } \\
\text { Problema de Engenharia }\end{array}$ & $\begin{array}{l}\text { Quais são as competências e habilidades que seus } \\
\text { funcionários possuem que os caracterizam como } \\
\text { ampla e empreendedora?(P) } \\
\text { Quais são as competências e habilidades que seus } \\
\text { funcionários possuem para identificar tendências e a } \\
\text { desenvolver novos produtos, processos e novos } \\
\text { mercados? (A) } \\
\text { Quais são as competências e habilidades que seus } \\
\text { funcionários possuem que os caracterizam como } \\
\text { especialistas e capazes de promover a defesa do nicho } \\
\text { de mercado? (D) } \\
\text { Quais são as competências e habilidades que seus } \\
\text { funcionários possuem que os caracterizam como } \\
\text { flexíveis? (R) }\end{array}$ \\
\hline Autores & Questões & Questões para Classificar o Comportamento \\
\hline $\begin{array}{l}\text { Saebi, Lien, Foss } \\
\text { (2017); }\end{array}$ & $\begin{array}{l}\text { 7. Proteção contra Concorrentes: } \\
\text { Níveis e composição de demanda / } \\
\text { efeitos dos preços dos concorrentes } \\
\text { / produtos substitutos / inovação e } \\
\text { certificação. } \\
\text { Problema de Engenharia }\end{array}$ & $\begin{array}{l}\text { Como a empresa desenvolve novos produtos, } \\
\text { processos e novos mercados de maneira consistente? } \\
\text { (P) } \\
\text { Quais são estas habilidades que sua empresa possui de } \\
\text { analisar tendências em desenvolvimento? } \\
\text { Como a empresa analisa tendências potencialmente } \\
\text { viáveis? (A) } \\
\text { Quais são os pontos em que a empresa se dedica e faz } \\
\text { excepcionalmente bem? }\end{array}$ \\
\hline
\end{tabular}




\begin{tabular}{|c|c|c|}
\hline & & $\begin{array}{l}\text { Como a empresa visualiza as tendências de mercado? } \\
\text { Quais são as respostas às tendências de mercado? (R) }\end{array}$ \\
\hline $\begin{array}{l}\text { Child, Hsieh e } \\
\text { Elbanna, et. al. } \\
\text { (2017) }\end{array}$ & $\begin{array}{l}\text { 8. Preparação para Futuro: } \\
\text { Número de pessoas em P\&D / } \\
\text { Número de novos produtos por } \\
\text { períodos / principais pontos fortes } \\
\text { no mercado / participação em } \\
\text { mercados internacionais }\end{array}$ & $\begin{array}{l}\text { Quais são as ferramentas que sua empresa utiliza para } \\
\text { expansão em novos mercados ou novos segmentos de } \\
\text { mercado? (P) } \\
\text { Como a empresa analisa as oportunidades no mercado } \\
\text { e escolhe apenas aquelas que apresentam potenciais? } \\
\text { (A) } \\
\text { Quais são as medidas de controle da produtividade e } \\
\text { qualidade que a empresa utiliza? (D) } \\
\text { Como a empresa faz a mediação entre o } \\
\text { monitoramento esporádico de mercado e a preparação } \\
\text { para horizontes futuros? (R) }\end{array}$ \\
\hline $\begin{array}{l}\text { Krishnamoorthi e } \\
\text { Mathew (2018); }\end{array}$ & $\begin{array}{l}\text { 9.Orientação da competição } \\
\text { Estrutura organizacional e } \\
\text { 10.Formas de Gerenciamento: } \\
\text { Cultura / Carreira das Equipes / } \\
\text { Treinamento / Características das } \\
\text { equipes e seus desempenho }\end{array}$ & $\begin{array}{l}\text { Em relação a competição - estrutura organizacional: } \\
\text { Como a empresa identifica tendências e oportunidades } \\
\text { no mercado e como viabiliza internamente ações } \\
\text { inovadoras ? (P) } \\
\text { Como a empresa monitora as outras empresas e quais } \\
\text { departamentos são líderes para estruturar respostas? } \\
\text { (A) Como a empresa identifica os problemas e quem } \\
\text { são seus principais observadores (departamentos)? (D) } \\
\text { Para a empresa, o que são problemas e desafios que } \\
\text { requerem atenção imediata? (R) }\end{array}$ \\
\hline $\begin{array}{l}\text { Heinzen et al. } \\
\text { (2016) }\end{array}$ & $\begin{array}{l}\text { 11.Procedimentos e avaliação de } \\
\text { desempenho: } \\
\text { Índices e medidas de valor }\end{array}$ & $\begin{array}{l}\text { Quais os controles que a empresa usa para avaliar seu } \\
\text { desempenho? (P) Por que os procedimentos são } \\
\text { centralizados em áreas } \\
\text { de produtos e processos mais estáveis e mais } \\
\text { participativos em áreas mais novas ou emergentes? } \\
\text { (A) Por que somente a alta gerência realiza } \\
\text { procedimentos para monitorar desempenho? Quais os } \\
\text { controles que a empresa usa para avaliar seu } \\
\text { desempenho? (D) }\end{array}$ \\
\hline
\end{tabular}

Quadro 4. Plano e Questões Avaliativas.

Fonte: Elaboração própria

Identificou-se os atores relevantes dentro da organização que tivessem como requisito o conhecimento das conexões entre o desafio empresarial de mercado e as relações subjacentes entre estrutura organizacional na sua forma administrativa e produtiva - de engenharia. Ajustou-se os elementos substantivos da literatura com os termos mais apropriados segundo a linguagem empresarial para obter maior domínio sobre o conhecimento tácito que se torna revelado pelo entrevistado. Finalmente, associou-se às questões uma classificação pertinente de comportamento (PDAR) para que o usuário do questionário venha a utilizar a pergunta, segundo nosso entendimento, correta uma vez que o interessado tenha identificado a predominância do seu próprio comportamento.

Com o plano de trabalho extraiu-se as questões para classificar o comportamento do entrevistado. 


\subsection{Contribuições Tecnológicas (I) - características das empresas entrevistadas, atores do processo decisório e formato das entrevistas}

Das quatro empresas participantes, entrevistamos dois Gerentes, um Diretor e um Presidente. Duas empresas têm tempo de atuação de até cinco anos e as outras duas atuam há mais de 10 anos no PCAC.

O número de funcionários e o volume de cabeças abatidas no programa refletem a diferença entre o porte das companhias consultadas. Uma empresa possui de 100 a 499 funcionários e as outras três, acima de 999 funcionários. Quanto ao abate anual, uma empresa abate 24 mil cabeças/ano; duas abatem 40 mil cabeças/ano; e a restante abate 250 mil cabeças/ano.

Como informação adicional, duas empresas possuem capital aberto e duas possuem capital fechado. Além disso, todas as empresas trabalham com a produção de carne de outras espécies animais, que não a bovina. Três empresas possuem unidades de produção também fora de São Paulo e uma concentra sua produção somente no Estado paulista. Por fim, o ano de fundação das empresas envolvidas neste estudo foram 1970, 1992, 2000 e 2005.

Os integrantes do Programa Carne Angus Certificada no Estado de São Paulo (recorte proposto no presente trabalho), foram escolhido segundo lista publicada pela ABA (2017d). A identidade dos participantes foi omitida, mas as empresas foram identificadas no início do trabalho. As entrevistas foram realizadas por videoconferência em duas oportunidades. A primeira para obtenção das respostas e a segunda para revisão das informações e do relato produzido. Cada uma das fases levou aproximadamente $20 \mathrm{~h}$ de trabalho, todas realizadas no mês de novembro de 2017.

A entrevista foi conduzida por meio das questões avaliativas do Quadro 4. As respostas foram avaliadas através da transcrição (análise de conteúdo). Meihy (1990) apresenta três formas de realizar a transcrição das entrevistas. A primeira forma é a Tradicional, que reproduz a fidelidade absoluta ao que foi dito, respeitando irrestritamente o que foi respondido pelo informante. A segunda forma é a Conciliatória, que estabelece uma média entre a resposta e o que foi verificado em documentos. E a última forma é a Livre, técnica que se rende às ideias e não às palavras. Foram utilizados neste estudo os conceitos de Meihy (1990) sobre a transcrição de entrevistas, adotando a terceira forma, a transcrição livre, que favorece as ideias transmitidas pelo entrevistados, sem a necessidade da transcrição palavra por palavra. 


\subsection{Contribuições Tecnológicas (II) - resultados como meio para comparação para outros estudos}

Estruturou-se as contribuições gerenciais para permitir a replicação do instrumental elaborado. Das Tabelas 1 e 2 ressalta-se a conexão do plano com as questões avaliativas. Os onze itens que compõem o plano de trabalho podem ser eleitos no conjunto ou parcialmente para serem replicados. A sequência pode facilitar o entendimento para aplicação do instrumento para ação estratégica.

\section{Atores políticos empresariais (diretores e gerentes):}

Identificação da Estrutura de Concorrência. Apontamento do número de firmas que representam o ambiente competitivo relevante e apuração do grau de capacidade ou domínio relativo de mercado.

Compreensão das Tipologias de Comportamento Estratégico. Análise ou diagnóstico promovido através de oficinas internas com os participantes para estabelecer uma simetria de conhecimento conceitual.

Diagnóstico da Estrutura Organizacional. Identificação dos atores capazes de assimilar em cada uma das áreas Empresarial, Administrativa e de Engenharia os conceitos acima e a forma de interação.

Aplicação das 11 Dimensões do Plano - Utilização ou adaptação das questões com organização em quadros sintéticos das respostas obtidas.

A Tabela 1 reúne os resultados da aplicação do plano de trabalho com as questões. $\mathrm{O}$ entrevistado ao ouvir as alternativas segundo a classificação prévia de comportamento manifestava aquela que era pertinente à sua realidade dentro da empresa. Com isso os registros obtidos das 11 questões foram distribuídos entre as três dimensões do ciclo adaptativo. 
O resultado abaixo pode ser elaborado a partir das evidências obtidas em práticas similares. O interessado estaria em busca de um diagnóstico e teria que estabelecer uma dinâmica para extrair interpretações isentas de sua equipe. O meio para aplicar o questionário pode ser facilitado através de contratação de um agente externo que venha conduzir, dentro das linhas gerais aqui expostas, o plano proposto.

As respostas estão na forma de proporção (número de respostas por tipologia de comportamento/total de respostas).

Tabela 1.

Núcleo das Contribuições e Resultados das Respostas por Tipologia de Comportamento.

\begin{tabular}{|c|c|c|c|c|c|}
\hline Questão & Assunto & Prospectora & Analítica & Defensiva & Reativa \\
\hline 1 & Produtos e processos & $1 / 4$ & $2 / 4$ & $1 / 4$ & 0 \\
\hline 2 & Imagem das empresas & $1 / 4$ & $2 / 4$ & 0 & $1 / 4$ \\
\hline 3 & Monitoramento de mercado & $3 / 4$ & 0 & $1 / 4$ & 0 \\
\hline 4 & Características que impactam a demanda dos \\
clientes & 0 & $4 / 4$ & 0 & 0 \\
\hline 5 & Perfil estratégico da empresa & $1 / 4$ & $3 / 4$ & 0 & 0 \\
\hline 6 & Competências dos funcionários de nível \\
\hline 7 & gerencial & $2 / 4$ & $1 / 4$ & $1 / 4$ & 0 \\
\hline 8 & Froteção contra os concorrentes & $4 / 4$ & 0 & 0 & 0 \\
\hline 9 & Forma de gerenciamento & $1 / 4$ & $1 / 4$ & $2 / 4$ & 0 \\
\hline 10 & Estrutura organizacional & $3 / 4$ & 0 & 0 & $1 / 4$ \\
\hline 11 & Procedimentos de avaliação de desempenho & 0 & $2 / 4$ & $1 / 4$ & 0 \\
\hline
\end{tabular}

Fonte: Elaboração própria

$\mathrm{Na}$ Tabela 2, agregou-se as respostas dos quatro entrevistados por dimensão - problema do ciclo adaptativo. Nessa ilustração, mais sintética, observa-se respostas com maior frequência de resultados prospectores e analíticos. As respostas aparecem como proporção de perguntas em cada uma das dimensões - problema e em porcentual para facilitar a interpretação.

\begin{tabular}{|c|c|c|r|r|r|}
\hline Questões & Problema & Prospectora & Analítica & Defensiva & Reativa \\
\hline 1 a 4 & Empresarial & $(5 / 16)$ & $(8 / 16)$ & $(2 / 16)$ & $(1 / 16)$ \\
& & $31,3 \%$ & $50,0 \%$ & $12,5 \%$ & $6,3 \%$ \\
\hline 5 a 7 & Engenharia & $(7 / 12)$ & $(4 / 12)$ & $(1 / 12)$ & $(0 / 12)$ \\
& & $58,3 \%$ & $33,3 \%$ & $8,3 \%$ & $0,0 \%$ \\
\hline 8 a 11 & Administrativo & $(5 / 16)$ & $(5 / 16)$ & $(4 / 16)$ & $(2 / 16)$ \\
& & $31,3 \%$ & $31,3 \%$ & $25,0 \%$ & $12,5 \%$ \\
\hline
\end{tabular}

Quadro 6. Respostas Agregadas Segundo a Classe de Problema e Classificadas por Comportamento

No problema empresarial, analisado através de perguntas sobre 1) produtos e processos; 2) imagem; 3) monitoramento de mercado; e 4) característica comercial, ganhou destaque a 
tipologia Analítica (50\%), seguido do perfil prospector (31,3\%). Isto indica uma característica de empresas com foco nos produtos, processos, imagem, e que buscam monitorar de perto as tendências de mercado e adotar inovações.

Para o problema de engenharia, composto por perguntas que avaliam 5) perfil estratégico; 6) habilidades e competências dos funcionários de nível gerencial; e 7) proteção da empresa contra os concorrentes, destacaram-se as frequências de 58,3\% para a Tipologia Prospectora (maior que a média global), 33,3\% para a Tipologia Analítica (próxima da média global), e de $8,3 \%$ para a Defensiva e $0,0 \%$ para a Reativa (menores que a média global). Tal distribuição de tipologias refletiu características relacionadas à cuidadosa análise de receitas e custos; às amplas habilidades do corpo gerencial da organização e a constante atenção aos novos negócios.

Por fim, para o problema administrativo, com questões sobre 8) forma de gerenciamento da empresa; 9) forma de preparação para o futuro; 10) estrutura organizacional da empresa; e 11) procedimentos de avaliação de desempenho, as Tipologias Prospectora e Analítica se destacaram (31,3\%), com porcentagens próximas das verificadas no resultado global. Já neste conjunto de perguntas, os perfis defensivo e reativo ganharam importância frente ao resultado geral, com frequências de 25,0\% e 12,5\%, respectivamente. Isso revela que, apesar da liderança dos tipos prospector e analítico, administrativamente, o setor também convive com problemas e desafios de curto prazo e, em algumas situações, exibe uma hierarquia e avaliação de resultados rígidos e centralizados.

\section{Conclusões e considerações finais}

Neste relato tem-se como principal contribuição gerencial a caracterização e detalhamento do comportamento estratégico dos frigoríficos que trabalham no Programa de Carne Angus Certificada em São Paulo. O estudo contribuiu com a forma de propor um meio para elaborar e identificar o comportamento estratégico tanto para empresas que já atuam no setor, como para autoavaliação para potenciais entrantes. Propõe-se um instrumento de pesquisa para investigação dos comportamentos estratégicos com aplicação para indústrias frigoríficas participantes de programas de certificação de carne bovina. Diante das contribuições recentes da literatura, o instrumento além de atualizado pode ser reproduzido para outros segmentos empresariais. $\mathrm{O}$ cuidado que o agente político empresarial que tomar tal iniciativa deve ter referem-se ao domínio das tipologias de comportamento; da estrutura organizacional e suas 
ramificações com ações estratégicas; formas eficientes e eficazes de monitorar as mudanças de mercado e o ciclo informacional dessas mudanças para dentro da estrutura da organização.

Dessa forma, esta avaliação pode ser replicada em situações semelhantes ou até mesmo serem atualizadas pelas empresas participantes do estudo.

A análise do comportamento estratégico apontou para um perfil predominantemente prospector e analítico, que indica uma atitude proativa, inovadora e minuciosa das empresas entrevistadas, características estas que são típicas de empresas que operam em novos nichos de mercado. Os atributos relacionados a este perfil foram expresso pela forma das perguntas e o registro das respostas.

Apesar da modernização do setor frigorífico no Brasil, segundo o resultado das entrevistas, existem melhorias a serem implementadas no campo dos problemas empresarial e administrativo. Embora minoritária, há um conjunto de respostas reativas, que segundo a literatura, é indesejável para empresas que atuam em nichos de mercado. A liderança e a inovação foram fatores identificados no trabalho como determinantes para a continuidade e melhoria dos procedimentos de certificação. A estratégia mercadológica enfática sobre as características do produto estão alinhadas com o planejamento estratégico das empresas, mas as respostas das empresas para a adaptação administrativa, de planejamento se mostrou desalinhado com o esforço metodológico.

Por se tratar de empresas de grande porte, acredita-se que uma avaliação comparativa por participantes do mercado poderá oferecer um meio de diagnosticar o próprio comportamento estratégico, de acordo com a Tabela 1. Com modificações pertinentes os resultados aqui sistematizados podem ser empregados para empresas de outros segmentos empresariais.

Finalmente, o Quadro 4 captura os principais núcleos das contribuições recentes e oferece a estrutura de questão pertinente ao comportamento lógico - fundamental do comportamento. Com as Tabelas 1 e 2 demonstra-se como organizar os resultados colhidos como meio para orientar os agentes empresariais em suas ações competitivas.

Ao reconhecer que o comportamento estratégico dentro das organizações continua a ser um desafio, o instrumento de pesquisa elaborado pode ser adaptado para servir aos atores empresariais, responsáveis em última instância pela capacidade de empregar e gerar lucros das empresas nos mais diversos segmentos empresariais. 


\section{Referências}

ABA. (2017a). Sobre o programa. Acesso em 13 de Outubro de 2017, disponível em Associação Brasileira de Angus: http://angus.org.br/carne-angus-2/sobre-o-programa/.

Anwar, J., Shah, S. \& Hasnu, S.(2016). Business strategy and organizational performance: measures and relationships. Pakistan Economic and Social Review, n.54, n.1, 97-122.

Berian, M. J., Sánchez, M., \& Carr, T. R. (2009). A comparison of consumer sensory acceptance, purchase intention, and willingness to pay for high quality United States and Spanish beef under different information scenarios. Journal of Animal Science , 87 (10), 3392-3402.

Carvalho, T. B. (2016). Estratégias de crescimento e reestruturação da indústria de carne bovina no Brasil: o papel de políticas públicas discricionárias. Faculdade de Economia, Administração e Contabilidade - Universidade de São Paulo, São Paulo.

Champredonde, M. (2008). The source and market development of a premium product: beef from the Argentine Pampas. Meat Science, 534-540.

Chandler, A. (1962). Strategy and Structure: chapters in the history of the industrial entreprise. MIT Press: Cambridge, Ma.

Child, J., Hsieh, L., Elbanna, S., Karmowska, J., Marinova, S., Puthusserry, P. Tsai., T., Narooz, R., Zhang, Y. (2017). SME international business models: the role of context and experience. Journal of World Business, 52, 664-679.

CONAB. (2017). Quadro de Suprimentos e Comércio Exterior. Acesso em 20 de outubro de 2017, disponível em Conab - Companhia Nacional de Abastecimento: http://www.conab.gov.br/conteudos.php?a=1538\&t $=2$.

DADF. (2016). Annual Report 2015-16. Ministry of Agriculture and Farmers Welfare of India, New Delhi.

Danmke, E.J. Gimenez, F.A.O, Damke, J.F. (2018). Strategic configurations and performance: a study in kicro and small business. RAUSP Management Journal, 55, $11-22$.

Hakansson, H., \& Snehota, I. (2006). No business is an island: The network concept of business strategy. Scandinavian Journal of Management, 22 (3), 256-270.

IBGE. (2016). Pesquisa Pecuária Municipal - PPM. Acesso em 12 de setembro de 2017, disponível em Sistema IBGE de Recuperação Automática - SIDRA: https://sidra.ibge.gov.br/pesquisa/ppm/quadros/brasil/2016.

Krishnamoorthi,S. \& Mathew, S. K. (2018). Business analytics and business value: a comparative case study. Information \& Management, In press. Recuperado https://doi.org/10.1016/j.im.2018.01.005.

Leonelli, F. C., \& Oliveira, I. R. (2016). Percepção dos consumidores sobre os açougues gourmet:um estido multicaso. Organizações Rurais \& Agroindustriais, 18 (1), 79-91.

Lopes, H. E., Moura, T. N., \& Oliveira, C. C. (2010). Os perfis estratégicos no Brasil: um estudo dos agentes franqueados dos correios a partir da tipologia de Miles e Snow. Revista Brasileira de Gestão de Negócios , 12 (37), 388-404.

Martinelli, R. R., Pigatto, G., \& Machado, J. d. (2015). Certificação privada coletiva como estratégia de diferenciação de produtos agroalimentares: o caso das Associações de Produtores de Carne Bovina. Revista Espacios, 36, 22 - 27.

Miles, R.E. \& Snow, C. C. (1978). Organizational Strategy, Structure, and Process. New York: McGraw-Hill.

Olson, E. M. Slater, S.F., Hult, \& T.M., Olson, K.M. (2018). The application of human resource management policies withn the marketing organization: the impact on business and marketing strategy implementation. Industrial Marketing Management, In press. Recuperado https://doi.org/10.1016/j.indmarman2018.01.029. 
Polkinghorne, R. J., \& Thompson, J. M. (2010). Meat standards and grading: a world view. Meat Science , 86 (1), 227-235.

Schnettler, B. (2014). Consumer preferences towards beef cattle in Chile: importance of country of origin, cut, packaging, brand and price. Revista de la Facultad de Ciencias Agrarias , 46 (1), 143-160.

Saebi, T., Lien., L. Foss, N. (2017). What drives model adaptation? the impact of opportunities, threats, and strategic orientation. Long Range Planning, v.50, 567-581.

Siebert, J. W., \& Jones, C. (2013). A Case Study on Building the Certified Angus Beef® Brand. International Food and Agribusiness Management Review, 16.

USDA. (2017). PSD Online. Acesso em 20 de setembro de 2017, disponível em United States Department of Agriculture - Foreign Agriculture Service: https://apps.fas.usda.gov/psdonline/psdquery.aspx.

Velean, D., Shoam, A., Asseraf, Y. Conceptualization of MILE orientation (Market Innovative Learning Entrepreneurial) for Global Business. Procedia - Social and Behavioral Sciences, 109 , p. $837-840$.

Wedekin, I. (2017). Economia da pecuária de corte: fundamentos e o ciclo de preços. São Paulo: Wedekin Consultores. 